\title{
MODIFICAÇÃO BIOQUÍMICA DA GORDURA DO LEITE
}

Gisele Fátima Morais Nunes, Ariela Veloso de Paula e Heizir Ferreira de Castro

Escola de Engenharia de Lorena, Universidade de São Paulo, CP 116, 12602810 Lorena - SP, Brasil

Júlio César dos Santos*

Departamento de Ciências Agrárias, Universidade de Taubaté, Estrada Dr. José Luiz Cembranelli, 5.000, 12081-010 Taubaté- SP, Brasil

Recebido em 17/4/09; aceito em 20/8/09; publicado na web em 8/1/10

BIOCHEMICAL MODIFICATION OF MILKFAT. Recent advances for improving physicochemical and nutritional properties of lipids are reviewed, with emphasis on products attaining by biochemical processing of natural fats and oils. Enzymatic interesterification provides an important route to modify physical and nutritional properties of milkfat without generating trans isomers. This process makes use of lipases, a versatile class of enzyme that is able to perform efficiently the target modification in both solvent and solvent free systems. The present review covers important features of lipases, lipase-catalyzed interesterification reactions and their effects on the composition and texture of the resulting product.

Keywords: milkfat; lipase; interesterification.

\section{INTRODUÇÃo}

As exigências do consumidor por produtos mais saudáveis, associadas às novas descobertas científicas sobre os efeitos na saúde humana de diversos alimentos, tradicionais ou desenvolvidos mais recentemente pela indústria, têm motivado a busca por processos adequados à produção de alimentos com características específicas. Entre eles, os óleos e gorduras modificados têm recebido especial atenção, graças à importância do consumo adequado dos mesmos na dieta visando a promoção e manutenção da saúde. Destaque pode ser dado aos novos conhecimentos sobre os efeitos metabólicos das gorduras saturadas e dos isômeros trans presentes em manteigas e margarinas.

A introdução dos ácidos graxos trans em quantidades consideráveis na dieta humana pode ser identificada com o desenvolvimento do processo de hidrogenação parcial de óleos vegetais para fabricação de margarinas ou shortening. ${ }^{1}$ Este processo consiste na inserção de átomos de hidrogênio às duplas ligações dos ácidos graxos presentes em óleos, obtendo-se produtos sólidos ou semissólidos com maior estabilidade em relação à oxidação e prolongando o tempo de prateleira. ${ }^{2}$

Os ácidos graxos trans são praticamente inexistentes em óleos e gorduras de origem vegetal não-refinados, entretanto estão presentes em pequenas quantidades em produtos derivados de leite e em outras gorduras de origem animal, devido à hidrogenação biológica no estômago dos ruminantes. ${ }^{3}$ As gorduras parcialmente hidrogenadas são as fontes principais destes ácidos, sendo encontradas em vários alimentos processados, como tortas, margarinas e produtos de panificação, ${ }^{3,4}$ contribuindo com cerca de 80 a $90 \%$ de todos os isômeros trans ingeridos numa dieta alimentar normal. ${ }^{3,5,6}$

Pesquisas têm mostrado que os ácidos graxos trans são tão ou mais prejudiciais à saúde do que os ácidos graxos saturados, principalmente no que diz respeito à elevação dos níveis de colesterol no sangue e, consequentemente, ao aumento do risco das doenças cardiovasculares. ${ }^{4,7} \mathrm{O}$ consumo de calorias provenientes de ácidos graxos trans tem sido relacionado ao aumento da lipoproteína de baixa densidade (LDL - Low Density Lipoprotein), e à redução da lipoproteína de alta densidade (HDL - High Density Lipoprotein), no plasma, resultando em elevação da relação LDL/HDL mais significativa do

*e-mail: jsant200@yahoo.com.br que a ingestão de ácidos graxos saturados e, consequentemente, em efeito adverso à saúde mais acentuado. ${ }^{4,6,7}$ Estudos têm revelado que o acréscimo de uma unidade nesta relação está associado à ascensão em cerca de $50 \%$ do risco de doenças cardiovasculares. ${ }^{5}$

Por outro lado, a associação entre a ingestão de gorduras trans e a incidência de doenças cardiovasculares não está ainda bem estabelecida e uma das explicações para esta inconsistência pode ser devida à fonte desses isômeros, já que as doenças coronarianas estão interligadas muito mais à ingestão das gorduras trans provenientes do processo de hidrogenação parcial do que aquelas advindas de produtos de origem animal. ${ }^{8} \mathrm{~A}$ diferença entre os ácidos graxos trans provenientes de gordura animal e os de gordura hidrogenada manufaturada não se refere apenas às quantidades, mas também ao tipo de isômero predominantemente encontrado em cada uma delas. Entre os ácidos graxos trans resultantes do processo de bio-hidrogenação, há o predomínio do ácido vacênico (C18:1-11t), enquanto na gordura que sofre hidrogenação parcial prevalece o ácido elaídico (C18:19t). Este é considerado o principal competidor do ácido linoleico no metabolismo humano, podendo esta ação refletir-se sobre a redução do número de receptores de lipoproteína de baixa densidade, contribuindo para o aumento de seus níveis plasmáticos. ${ }^{9}$

Além das doenças cardiovasculares, a ingestão de gorduras trans tem sido correlacionada à incidência de outros malefícios à saúde, como o aparecimento de asmas e alergias em crianças, ${ }^{1,10}$ a ocorrência de diabetes em adultos ${ }^{10} \mathrm{e}$ a inibição do metabolismo de ácidos graxos essenciais influenciando o desenvolvimento infantil. . $^{5,11,12}$

Muitos países têm mostrado significativa preocupação com respeito às informações nutricionais nas rotulagens de alimentos embalados, com a criação de legislações que evidenciem essa inquietude com a saúde futura. ${ }^{13}$ Baseada em estudos recentes, a Organização Mundial da Saúde recomenda que o consumo máximo deste tipo de gordura não deve ser superior a $1 \%$ das calorias totais ingeridas. ${ }^{6}$

Os produtos originados de óleos hidrogenados começaram a serem produzidos no início do século XX, objetivando-se substituir a manteiga que era um produto de alto valor agregado. ${ }^{14}$ Contudo, em função de todos os inconvenientes recentemente descobertos, causados pela ingestão de gorduras provenientes de óleos vegetais hidrogenados, tem-se buscado a substituição do processo de hidrogenação parcial por vias de produção que não resultem em formação de isômeros trans. 
Neste contexto, a gordura do leite tem tido destaque novamente em diversos estudos recentes, ${ }^{15-22}$ visando a obtenção de produtos que aliem o sabor desta matéria-prima lipídica com as características físicas e de composição (menor teor de gordura saturada, presença de ácidos graxos essenciais) desejáveis para o consumidor. Isto pode ser alcançado pela mistura da gordura do leite com óleos vegetais, possibilitando a aquisição de lipídeos com melhores características nutricionais pelo aumento da quantidade de gordura insaturada e com melhores propriedades de espalhabilidade sob temperatura de refrigeração doméstica. Esta mistura, quando associada à interesterificação, pode resultar em diminuição na dureza e no caráter sólido da gordura do leite pela indução da queda na quantidade de sólidos presentes e mudança na estrutura da rede cristalina. ${ }^{23}$

Esta revisão teve como objetivo descrever, comparar e discutir o estado da arte deste processo, evidenciando sua importância para a obtenção de produtos com características físicas e nutricionais desejáveis, sem a geração de gorduras trans. O reconhecimento dessas vantagens tem proporcionado aumento considerável no desenvolvimento de tecnologias consistentes de interesterificação enzimática da gordura do leite.

\section{GORDURA DO LEITE}

O leite tem sido descrito como um dos alimentos naturais mais próximos da perfeição, devido particularmente ao seu elevado teor de nutrientes, incluindo proteínas, gorduras, açúcares, minerais e vitaminas. Sua gordura é uma importante fonte de lipídeos na dieta e possui maravilhoso sabor e aroma. ${ }^{24}$

A gordura do leite é uma mistura de mais de 100.000 tipos de triacilgliceróis nos quais estão distribuídos diferentes ácidos graxos (Tabela 1), sendo provavelmente a mais complexa de todas as gorduras naturais. ${ }^{24}$ Essa composição tão variada é responsável por propriedades organolépticas, físicas e nutricionais exclusivas. ${ }^{25}$ Este alimento é uma mistura de fases sólidas e líquidas, sendo completamente sólido a $-40{ }^{\circ} \mathrm{C}$ e completamente líquido a $38^{\circ} \mathrm{C} .{ }^{26}$

Tabela 1. Composição em ácidos graxos da gordura do leite (\% em massa). Adaptada da ref. 27

\begin{tabular}{lcc}
\hline Ácidos Graxos & C $4: 0$ & $\begin{array}{c}\text { Composição } \\
\text { gordura do leite } \\
(\%)\end{array}$ \\
\hline Butírico & C $6: 0$ & $2,8-4,0$ \\
Caproico & C $8: 0$ & $1,4-3,0$ \\
Caprílico & C $10: 0$ & $0,5-1,7$ \\
Cáprico & C $12: 0$ & $1,7-3,2$ \\
Láurico & C $14: 0$ & $2,2-4,5$ \\
Mirístico & C $14: 1$ & $5,4-14,6$ \\
Miristoleico & C $16: 0$ & $0,6-1,6$ \\
Palmítico & C $16: 1$ & $25,0-41,0$ \\
Palmitoleico & C $18: 0$ & $2,0-6,0$ \\
Esteárico & C $18: 1$ & $6,0-11,0$ \\
Oleico & C $18: 2$ & $18,7-33,4$ \\
Linoleico & C $18: 3$ & $0,9-3,7$ \\
Linolênico & & 0,5 \\
Saturados & & $45,0-83,0$ \\
Insaturados & & $22,7-45,2$ \\
\hline
\end{tabular}

Durante algum tempo essa gordura foi apontada como prejudicial à saúde por conter quantidades razoáveis de colesterol e ácidos graxos saturados, os quais têm implicação no aumento de doenças cardiovasculares, sendo este fator relevante para a substituição da manteiga por outros produtos. $\mathrm{O}$ efeito hipercolesterolêmico da gordura do leite na dieta humana é associado principalmente aos ácidos láurico, mirístico e palmítico. ${ }^{28}$

Por outro lado, deve-se ressaltar que esta gordura possui componentes benéficos e importantes para a manutenção da saúde e redução do risco de doenças. Nela encontram-se quantidades apreciáveis de ácidos linoleicos conjugados (Conjugated Linoleic Acid - CLA), um grupo de ácidos graxos que desempenham importantes efeitos à saúde, incluindo o combate a diabetes e à obesidade, a modulação do sistema imunológico e do crescimento ósseo, ${ }^{29} \mathrm{e}$ sua ação anticarcinogênica, principalmente no que diz respeito ao câncer de mama. ${ }^{30}$ Igualmente benéfico é o ácido butírico, que tem sido sugerido como potente inibidor da proliferação de células cancerígenas e indutor da diferenciação e apoptose de diferentes linhagens destas células. ${ }^{31,32}$

As características nutricionais, todavia, não são suficientes para a aceitabilidade de um produto, sendo também fundamental que sejam considerados aspectos como propriedades físicas e organolépticas de um alimento. Ao contrário da margarina, a manteiga tem faixa de plasticidade limitada, comportando-se como um sólido pouco espalhável à temperatura de refrigeração $\left(0-10^{\circ} \mathrm{C}\right)$, enquanto que à temperatura ambiente $\left(20-25^{\circ} \mathrm{C}\right)$ há separação do óleo e exsudação. Sua espalhabilidade ideal ocorre em torno de $15^{\circ} \mathrm{C}$, temperatura na qual seu conteúdo de gordura sólida está em torno de $30 \% .^{25}$

Buscando-se obter um produto que alie os atributos organolépticos e de composição da gordura do leite, mas que contenha menores quantidades de ácidos graxos saturados e que possua melhor espalhabilidade à temperatura de refrigeração, têm sido realizados estudos objetivando-se sua modificação. Dentre os processos em estudo, destaca-se a interesterificação, a qual pode ser química ou enzimática. ${ }^{33,34} \mathrm{~A}$ Figura 1 apresenta um fluxograma representativo das rotas química e bioquímica para obtenção de um produto alimentício a partir da interesterificação da gordura do leite com óleo vegetal.

A rota química, em geral, utiliza como catalisador sódio metálico e metilato de sódio, ${ }^{14,35}$ conduzindo a redistribuição aleatória dos ácidos graxos nas cadeias dos triacilgliceróis. A via enzimática faz uso de lipases como biocatalisador; nela, os ácidos graxos podem ser redistribuídos, de forma aleatória empregando-se lipases não específicas, ou em posições características, quando são utilizadas enzimas específicas. ${ }^{36}$

Ambas as vias, química ou enzimática, podem ser utilizadas na indústria de óleos e gorduras para a fabricação de margarinas e shortenings. ${ }^{34}$ Entretanto, deve-se destacar que a rota enzimática possui vantagens se comparada à química (Figura 1), tais como a reogioespecifidade que permite maior controle sobre a distribuição posicional dos ácidos graxos no produto final, além de empregar condições de reação mais suaves (temperaturas reduzidas), que podem ser menos prejudiciais às qualidades organolépticas da manteiga. ${ }^{15,26}$

\section{CATALISADOR BIOQUÍMICO}

Lipases são enzimas classificadas como hidrolases (triacilglicerol acil-hidrolases, EC 3.1.1.3) e atuam na hidrólise de triacilgliceróis formando ácidos graxos livres e glicerol em meio aquoso ou na reação inversa em meio orgânico. Estes biocatalisadores são comumente encontrados na natureza, podendo ser obtidos a partir de fontes animais, vegetais ou microbianas. ${ }^{35,37}$ As lipases provenientes de microorganismos são as mais utilizadas industrialmente, por apresentarem procedimentos mais simples de isolamento e serem mais estáveis e terem propriedades bem mais diversificadas que as de outras fontes. ${ }^{36}$ Estas enzimas não requerem cofatores, são regioespecíficas, atuam em larga faixa de $\mathrm{pH}^{38} \mathrm{e}$ apresentam a capacidade única de atuar apenas na interface óleo/água. ${ }^{39}$ 


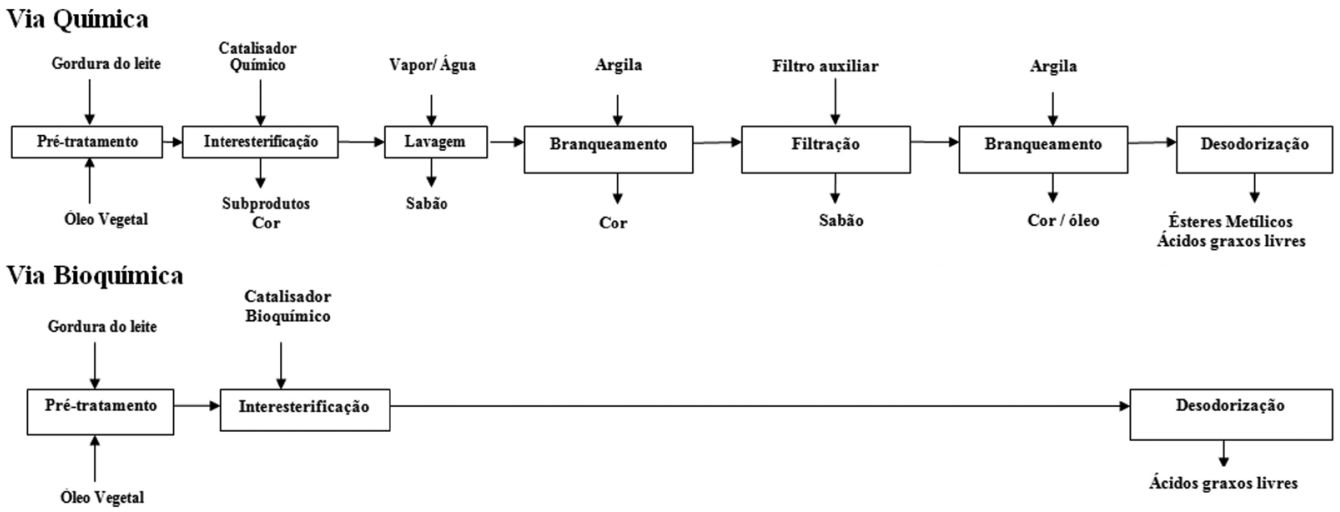

Figura 1. Comparação das rotas química e bioquímica para obtenção de produto alimentício a partir da interesterificação da gordura do leite e óleo vegetal

Com relação à especificidade, a literatura relata que é controlada pelas propriedades moleculares da enzima, estrutura do substrato e por fatores que afetam a ligação enzima-substrato. ${ }^{40}$ As lipases podem ser classificadas de acordo com sua especificidade posicional (não específicas ou 1,3-específicas) ou quanto à especificidade por ácidos graxos ${ }^{35,36}$ (Tabela 2). Além disso, lipases podem apresentar especificidade estereoquímica, atuando particularmente sobre um isômero óptico. ${ }^{41}$

A versatilidade das lipases permite que estas enzimas sejam selecionadas para aplicações potenciais em diversos setores, como alimentício, de detergentes, farmacêutico, têxtil, cosmético, combustível e indústrias de papel, entre outros. ${ }^{42}$ Para o setor de alimentos, em especial, lipases de grau alimentício têm sido empregadas. ${ }^{43}$

Lipases estão disponíveis comercialmente nas formas livre e imobilizada, sendo que para aplicações industriais é recomendado o uso de lipases na forma imobilizada. Os métodos de imobilização, ${ }^{44-46}$ tipos de suporte, ${ }^{46,47}$ e aplicações desses sistemas ${ }^{38,42,46}$ são amplamente descritos na literatura.

Lipases pertencem a um grupo de enzimas interessantes não apenas pela capacidade de atuarem sobre substratos insolúveis em água, mas também pela capacidade de catalisarem diferentes reações, tais como hidrólise, esterificação e interesterificação (alcoólise, acidólise e transesterificação). ${ }^{48} \mathrm{~A}$ interesterificação em especial tem sido o método mais usado para obtenção de óleos e gorduras com funções desejáveis para a manufatura de produtos específicos. ${ }^{35}$

\section{MODIFICAÇÃO BIOQUÍMICA DA GORDURA DO LEITE}

A interesterificação consiste de uma reação que promove a troca e redistribuição dos ácidos graxos entre os triacilgliceróis até que equilíbrio termodinâmico seja alcançado, resultando em produtos que apresentam a mesma composição em ácidos graxos, porém com diferente composição em triacilgliceróis e, consequentemente, com diferentes características físicas e nutricionais. . $^{33,49,50}$

Nutricionalmente, esta reação promove benefícios quando comparada à hidrogenação, pois o processo de rearranjo dos ácidos graxos não altera sua isomeria ou seu grau de insaturação, ${ }^{33}$ o que leva à geração de produtos com quantidade reduzida ou livre de isômeros trans e que podem possuir maiores concentrações de ácidos graxos poli-insaturados. ${ }^{5}$

O uso da interesterificação é uma tendência que se apresenta como alternativa promissora na indústria de gorduras para alterar também propriedades de espalhabilidade, pois modifica substancialmente as propriedades físicas das gorduras. ${ }^{25}$

A velocidade de reação, o rendimento do processo e a obtenção dos produtos desejados dependem de alguns fatores cruciais para a realização de reações de interesterificação (Figura 2). A matériaprima e a preparação de lipase devem ser escolhidas adequadamente para atingir a viabilidade técnica e econômica do processo. O biocatalisador deve ser imobilizado para melhorar sua estabilidade e eficiência catalítica. Em seguida, as condições reacionais devem ser estabelecidas, incluindo a necessidade de adição de solvente orgânico, a otimização da proporção mássica das matérias-primas, temperatura, quantidade de biocatalisador no meio reacional e configuração do reator, entre outros fatores.

Visando identificar a influência desses parâmetros na eficiência da interesterificação enzimática da gordura do leite foi realizada uma pesquisa bibliográfica em diferentes bases de dados científicas (ISI Web of Knowledge, Scopus, Scifinder Scholar) no período entre 1986 a 2008, utilizando como palavras-chaves: interesterificação enzimática, gordura do leite e lipases. Alguns dos principais trabalhos encontrados são apresentados na Tabela 3, dispostos em ordem cronológica,

Tabela 2. Classificação das lipases de acordo com sua especificidade. Adaptada das refs. 35 e 36

\begin{tabular}{|c|c|c|}
\hline Lipase & Atuação & Exemplos \\
\hline Não específicas & $\begin{array}{l}\text { Catalisam a hidrólise de TAG gerando ácidos graxos livres e } \\
\text { glicerol, de modo aleatório. }\end{array}$ & $\begin{array}{c}\text { Candida cylindracea } \\
\text { Penicilium cyclopium, Staphylococcus aureus } \\
\text { Corynebacterium acnes Pseudomonas fluorescens }\end{array}$ \\
\hline \multirow{5}{*}{ 1,3-específicas } & \multirow{5}{*}{$\begin{array}{l}\text { Catalisam a hidrólise de TAG gerando ácidos graxos livres } \\
\text { provenientes especificamente das posições } s n-1 \text { e } s n-3 \text {. }\end{array}$} & $\begin{array}{l}\text { Mucor miehei } \\
\text { Rhizopus oryzae }\end{array}$ \\
\hline & & Aspergillus niger \\
\hline & & Rhizopus delemar \\
\hline & & Lipase pancreática \\
\hline & & Penicillium roquefortii \\
\hline Ácido graxo específicas & $\begin{array}{l}\text { Catalisam a hidrólise de tipos específicos de ácidos graxos nas } \\
\text { moléculas de TAG. }\end{array}$ & Geotrichum candidum \\
\hline
\end{tabular}




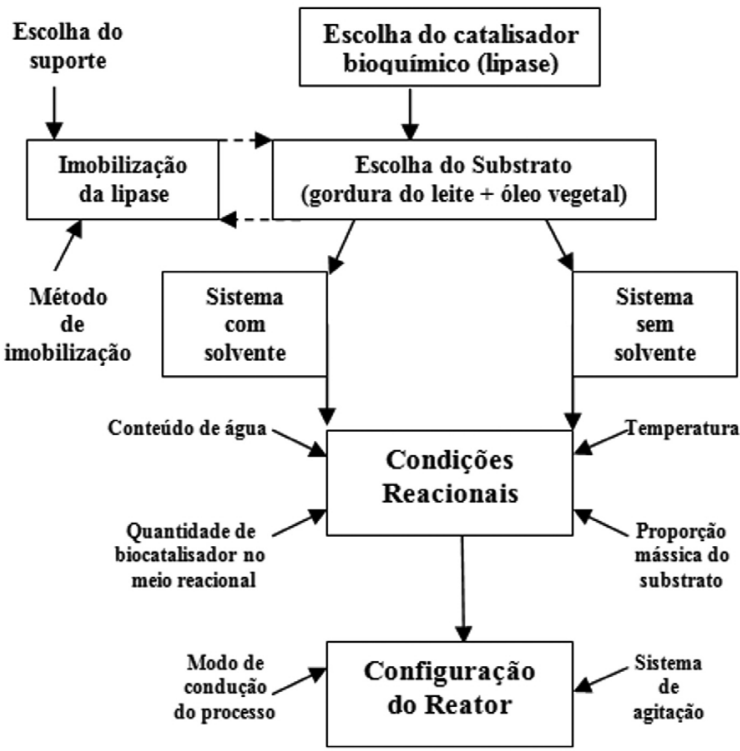

Figura 2. Principais parâmetros que interferem na interesterificação da gordura do leite pela rota bioquímica

com os resultados mais relevantes descritos pelos autores. Os demais trabalhos encontram-se dispostos no material suplementar na versão on-line da revista.

Observou-se aumento no número de publicações nos últimos 30 anos, sendo que 53\% do total de artigos encontrados sobre o tema em estudo foram publicados entre 2000-2008.

Nos trabalhos pioneiros efetuados na década de 80 a modificação enzimática era conduzida com a gordura do leite pura, ${ }^{55-59}$ e apenas a partir dos anos 90 outros componentes foram misturados a esta gordura para a interesterificação. ${ }^{51,53,60-63}$ Os óleos vegetais mais utilizados foram os de colza, ${ }^{15,17-19,21,22,64-67}$ canola, ${ }^{53,60-63}$ e girassol. ${ }^{16,17,64,68,69}$ O maior uso do óleo de colza pode ser justificado pelo fato de que este óleo já é empregado comercialmente na preparação de spreads à base de gordura do leite. ${ }^{15}$

Destaque pode ser dado ao trabalho recente, desenvolvido por Aguedo et al. ${ }^{22}$ no qual se empregou óleo de linhaça, um óleo importante nutricionalmente por apresentar alto conteúdo de ácidos graxos insaturados $\mathrm{C}_{18}$ [ácidos linolênico $\left(\mathrm{C}_{18: 3}\right)$, linoleico $\left(\mathrm{C}_{18: 2}\right)$, e oleico $\left(\mathrm{C}_{18: 1}\right)$ ]. Entretanto, o uso deste óleo em alimentos é limitado em alguns países devido à sua instabilidade. ${ }^{22}$ Como forma de minimizar este problema os autores utilizaram misturas ternárias de gordura do leite com óleos de linhaça e colza.

Até o final da década de 1990, a maior parte dos pesquisadores utilizava a técnica de adsorção para a imobilização das enzimas adquiridas sob a forma livre que catalisavam a interesterificação da gordura do leite e como suportes empregavam Celite,,$^{51,55-60}$ e polipropileno. ${ }^{53,61-63,70}$ Nos trabalhos desenvolvidos a partir de 2000, verificase o uso predominante de enzimas já adquiridas comercialmente na forma imobilizada. ${ }^{15-22,64-66,71}$

As enzimas mais empregadas para catálise da reação em estudo foram as lipases de Mucor miehei (anteriormente Rhizomucor miehei) ${ }_{15,56,60,66-69,71-75} R$. oryzae (anteriormente $R$. javanicus, $R$. arrizus) ${ }^{53,61-63,76}$ e Candida antarctica. ${ }^{15-17,65,67,69,72}$

Alguns autores avaliaram o uso de diferentes fontes de lipase comparativamente, tais como Kalo et al. ${ }^{56}$ que utilizaram as lipases de M. miehei e Aspergillus niger, obtendo resultados em composição de triacilgliceróis semelhantes para ambas as fontes de enzima, mesmo a temperaturas de trabalho diferentes e com distintas técnicas de imobilização. No trabalho desenvolvido por Lai et al ${ }^{54}$ sete diferentes fontes de lipases foram empregadas e apresentaram desempenhos distintos, sendo que o melhor desempenho foi constatado para lipase de Pseudomonas sp., alcançando o mais elevado grau de interesterificação.

Os estudos realizados envolvendo as reações de interesterificação enzimática da gordura do leite foram conduzidos em sua maioria em reatores operando em regime de batelada com velocidades de agitação que variam de $100^{60}$ a $400 \mathrm{rpm} .{ }^{15}$ Podem-se destacar os trabalhos realizados por Ronne et al. ${ }^{15,19} \mathrm{e}$ Zhang et al. ${ }^{18}$ nos quais as reações foram conduzidas em reatores de leito empacotado e por Balcão et $a l .,{ }^{52}$ no qual foi empregado reator do tipo fibra oca. Reatores de leito empacotados têm sido utilizados em trabalhos de pesquisa recentes tendo em vista que este processo é muito usado para fins comerciais, pois permite operações de forma contínua, o que industrialmente é mais viável. ${ }^{15,18}$

Como condições reacionais, estudos mostram que a reação de interesterificação enzimática da gordura do leite pode ser conduzida em temperaturas que oscilam desde $35^{56}$ até $80^{\circ} \mathrm{C}^{16,17,66,72} \mathrm{e}$ em valores de $\mathrm{pH}$ que oscilam de 6 a $8 .^{61-63} \mathrm{O}$ uso de solvente é variável e, quando presente, os mais comumente utilizados são hexano,,$^{52,55} \mathrm{e}$ iso-octano. ${ }^{56,58,59} \mathrm{O}$ hexano também pode ser empregado em combinação com outros solventes, tais como clorofórmio e acetato de etila, como no trabalho desenvolvido por Safari et al. ${ }^{68}$ no qual esta mistura promoveu aumento do rendimento de interesterificação.

Em outro estudo realizado por Yu et al. ${ }^{51}$ foi utilizado o dióxido de carbono supercrítico, solvente geralmente recomendado nos setores de alimentos e farmacêutico. Comparado aos solventes líquidos, dióxido de carbono supercrítico não é tóxico, possui baixa viscosidade, altas taxas de difusão e transferência de massa, propriedades que são adequadas para reações enzimáticas. ${ }^{51}$ É um solvente que possui baixo valor agregado, não é inflamável e é lipofílico. ${ }^{77}$ Apresenta temperatura crítica relativamente baixa $\left(31,2{ }^{\circ} \mathrm{C}\right)$, que permite que não haja degradação térmica de produtos termossensíveis. ${ }^{78}$ Além disso, devido à facilidade de separação dos produtos reacionais, é considerado extremamente atrativo para uso como solvente em processos químicos ecologicamente mais aceitáveis. Entretanto, tem também desvantagens, como a redução da atividade catalítica, a qual tem sido atribuída à formação de ácido carbônico. ${ }^{77}$

Os métodos de análise mais utilizados para avaliação dos produtos resultantes da interesterificação enzimática da gordura do leite são cromatografia em fase gasosa para quantificação dos mono-, di- e triacilgliceróis, ressonância magnética nuclear (RMN) para a quantificação do conteúdo de gordura sólida, titulação para a determinação do conteúdo de ácidos graxos livres e calorimetria exploratória diferencial (Differential scanning calorimetry, DSC) para análise do comportamento térmico dos produtos interesterificados.

Pode ser dado destaque ao estudo desenvolvido por Zhang et $a l .,{ }^{18}$ no qual nova abordagem é dada ao monitoramento da reação aplicando-se a espectroscopia de transformada de Fourier no infravermelho próximo (Fourier transform near-infrared spectroscopy, FT-NIR). Os autores utilizaram a lipase de Thermomyces lanuginosa para catalisar a interesterificação da gordura do leite com óleo de colza em reator de leito empacotado. A reação foi monitorada por FT-NIR para obtenção do grau de conversão e do conteúdo de gordura sólida das misturas e produtos interesterificados. Foi observada boa correlação entre os resultados obtidos por NIR e os resultados de conversão obtidos pela razão de pico, calculado pelo perfil de triacilgliceróis, e os resultados de conteúdos de gordura sólida a $5{ }^{\circ} \mathrm{C}$, obtidos por $\mathrm{RMN}$.

Alguns autores estudaram comparativamente o emprego da interesterificação química e enzimática. Kalo et al.,${ }^{55}$ por exemplo, investigaram o uso de catalisador químico em relação à atuação da lipase de $C$. cilyndracea imobilizada por adsorção em Celite na interesterificação da gordura do leite pura, com reações realizadas 
Tabela 3. Exemplos de estudos realizados sobre interesterificação enzimática da gordura do leite

\begin{tabular}{|c|c|c|c|c|}
\hline Biocatalisador & Matérias-primas & Condições reacionais & Principais Resultados & Ref. \\
\hline $\begin{array}{l}\text { C. cilyndracae imobili- } \\
\text { zada em Celite }\end{array}$ & $\begin{array}{l}\text { Gordura do leite } \\
\text { Óleo de canola }\end{array}$ & $\begin{array}{l}40^{\circ} \mathrm{C} \text {; sob } 30 \mathrm{MPa} \text {; solvente }\left(\mathrm{CO}_{2}\right. \\
\text { upercrítico). }\end{array}$ & 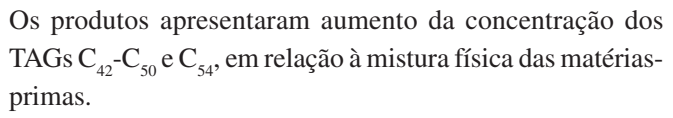 & 51 \\
\hline $\begin{array}{l}\text { Mucor javanicus imobi- } \\
\text { lizada por adsorção em } \\
\text { fibras de polipropileno }\end{array}$ & Gordura do leite & $\begin{array}{l}40{ }^{\circ} \mathrm{C} \text {; sem solvente; reator de } \\
\text { fibra oca. }\end{array}$ & $\begin{array}{l}\text { O produto apresentou uma faixa de fusão mais ampla que a } \\
\text { gordura do leite antes da reação. O total de TAGs saturados } \\
\text { decresceu } 2,2 \% \text {, enquanto que os TAGs } \mathrm{C}_{28}-\mathrm{C}_{46} \text { (que contêm } \\
\text { ácidos láurico, mirístico ou palmítico) decresceram } 13 \% \text {. }\end{array}$ & 52 \\
\hline $\begin{array}{l}\text { R. arrhizus imobilizada } \\
\text { em polipropileno }\end{array}$ & $\begin{array}{l}\text { Gordura do leite } \\
\text { Óleo de canola }\end{array}$ & Frascos agitados $50^{\circ} \mathrm{C}$. & $\begin{array}{l}\text { Os produtos interesterificados apresentaram redução no CGS } \\
\text { na faixa de } 5-40{ }^{\circ} \mathrm{C} \text { e nos pontos de amolecimento (softening } \\
\text { points) comparativamente às amostras não interesterificadas. } \\
\text { A análise de textura revelou que os produtos apresentaram } \\
\text { aumento na profundidade de penetração do cone em relação } \\
\text { às amostras antes da reação. }\end{array}$ & 53 \\
\hline
\end{tabular}

\begin{tabular}{lll}
\hline A. niger, M. javanicus & Gordura do leite & Frascos agitados $(200 \mathrm{rpm})$; sem \\
R. javanicus, R.niveus, & estearina de palma & solvente; $60^{\circ} \mathrm{C}$.
\end{tabular}

Alcaligenes sp. Pseu-

Os resultados indicaram que a lipase de Pseudomonas sp. 54

domonas sp.; C. rugosa

imobilizadas em Celite

Lipozime IM 60

produziu o mais alto grau de interesterificação $(33,9 \%)$

seguida pela lipase de $R$. miehei $(32,3 \%)$. A maior quantidade de AGL foi liberada pela reação catalisada por lipase de Pseudomonas sp. $(2,61 \%)$ seguida pelas lipases de Alcaligenes $(2,56 \%)$ e $R$. miehei $(2,18 \%)$.

\begin{tabular}{lll}
\hline Lipozyme TL IM ; T. & Gordura do leite & Batelada; frascos agitados (400 \\
lanuginosus imobilizada & Óleo de colza & $\mathrm{rpm}) ; 50{ }^{\circ} \mathrm{C}$. Reator de leito \\
em Accurel EP100; Li- & & empacotado $60{ }^{\circ} \mathrm{C}$.
\end{tabular}

Entre as lipases avaliadas, as Lipozymes TM IM e RM IM 15 foram escolhidas para os estudos adicionais no reator contínuo de leito empacotado. A lipase TM IM realizou a reação de forma mais rápida. Em relação aos AG da posição $s n-2$, observou-se redução do conteúdo de AG saturados (C14:0 e C16:0) e aumento dos AG de cadeia longa saturados e insaturados (C18:0 e C18:1).

zym 435; Burkholderia cepacia PS-C-I e PS-D-I

\begin{tabular}{|c|c|c|c|c|}
\hline Lipozyme TL IM & $\begin{array}{l}\text { Gordura do leite } \\
\text { Óleo de colza }\end{array}$ & $\begin{array}{l}\text { Reator de leito empacotado; } \\
70^{\circ} \mathrm{C} \text {. }\end{array}$ & $\begin{array}{l}\text { O trabalho demonstrou a viabilidade da aplicação de espec- } \\
\text { troscopia de infravermelho por transformada de Fourier para } \\
\text { o monitoramento da reação. }\end{array}$ & 18 \\
\hline Lipozyme TL IM & $\begin{array}{l}\text { Gordura do leite } \\
\text { Óleos de linhaça } \\
\text { e colza }\end{array}$ & $\begin{array}{l}\text { Batelada; agitador do tipo hélice; } \\
\text { nitrogênio gasoso. }\end{array}$ & $\begin{array}{l}\text { A reação atingiu o equilíbrio entre } 4 \text { a } 6 \text { h. O decréscimo no } \\
\text { CGS e no dropping point obtido com aumento no conteúdo } \\
\text { de óleo de linhaça e interesterificação resultou em boas } \\
\text { propriedades plásticas para os produtos das misturas binárias } \\
\text { contendo } 70: 30 \text { e } 60: 40 \text { de gordura do leite e óleo de linhaça, } \\
\text { resultados estes confirmados pela textura. A mistura ternária } \\
\text { apresentou propriedades reológicas e oxidativas satisfatórias. }\end{array}$ & 22 \\
\hline
\end{tabular}

TAGs = Triacilgliceróis; AGL= Ácidos graxos livres; AG= Ácidos graxos; CGS= Conteúdo de gordura sólida .

em frascos agitados, em meio isento ou na presença de solvente (hexano) a $60^{\circ} \mathrm{C}$. Os resultados mostraram que os produtos obtidos por catálise química e enzimática foram bastante similares em composição, visto que a lipase empregada não apresentou especificidade sob as condições estudadas. Entretanto, a gordura interesterificada com biocatalisador apresentou-se mais macia devido à presença de mono e diacilgliceróis formados.

Em outro trabalho, Brys et al. ${ }^{65}$ examinaram o emprego de catalisador químico comparativamente ao uso da lipase de $C$. antarctica imobilizada comercialmente (Novozym 435) na interesterificação da gordura do leite com óleo de colza, sendo a reação realizada a $60{ }^{\circ} \mathrm{C}$ por até $8 \mathrm{~h}$. Foi verificado que ambas as vias conduziram ao aumento do conteúdo de ácidos graxos livres e de frações polares (mono e diacilgliceróis). Entretanto, neste caso a via química foi a que apresentou os teores mais elevados destes compostos.

Outro aspecto importante, que deve ser considerado em relação à interesterificação de gordura do leite, é a manutenção de seu aroma já que o processo enzimático, devido à elevada formação de ácidos graxos livres, promove o surgimento de odor desagradável no produto final.
Rousseau e Marangoni ${ }^{53}$ investigaram as mudanças promovidas pela interesterificação enzimática no aroma da gordura do leite comparativamente a esta mesma reação realizada pela via química e os resultados mostraram que ambas apresentaram redução do aroma da manteiga, sendo que a via enzimática foi a que apresentou maior diminuição desta propriedade. Ronne et al. ${ }^{19}$ estudaram a influência desta reação sobre as propriedades organolépticas da gordura do leite e de suas misturas com óleo de colza, analisando os efeitos de diferentes condições de desodorização, temperatura e pressão sobre o aroma do produto final, com objetivo de obter as melhores condições de refino do produto, para remoção dos odores formados.

Entre as características que devem ser consideradas na condução da interesterificação enzimática da gordura do leite estão suas propriedades físicas, as quais são muito importantes na determinação da adequação desta gordura aos seus vários usos. Muitas pesquisas que relacionam a influência desta reação sobre as características físicas do produto obtido têm sido desenvolvidas e, neste sentido, as propriedades mais estudadas são o conteúdo de gordura sólida, ${ }^{56,58,62,63,70}$ as propriedades térmicas e de cristalização, ${ }^{52,62,70}$ o polimorfismo ${ }^{62,63} \mathrm{e}$ as análises de textura, que estão entre as principais técnicas utilizadas 
para verificar a melhora da espalhabilidade destes produtos ${ }^{53,62,63,22,75}$ sob temperatura de refrigeração.

Rousseau e Marangoni ${ }^{62}$ estudaram a interesterificação enzimática da mistura de gordura do leite e óleo de canola para avaliar o potencial da lipase de R. arrhizus como agente modificador da textura da manteiga. Os estudos permitiram concluir que este processo é uma ferramenta viável para modificar as propriedades de textura deste produto, resultando na redução da dureza e do caráter sólido da gordura do leite pela queda na quantidade de sólidos presentes e pequena mudança na estrutura da rede cristalina. Em outro trabalho, estes mesmos pesquisadores ${ }^{68}$ investigaram o efeito da interesterificação química e enzimática sobre as propriedades físicas da gordura do leite pura e de sua mistura com óleo de canola. Na rota enzimática foi utilizada a lipase de $R$. arrhizus imobilizada por adsorção em polipropileno. Estes autores verificaram que os produtos interesterificados com biocatalisador apresentaram redução nos pontos de amolecimento (softening points) em relação às amostras não interesterificadas, enquanto que os produtos obtidos por via química apresentaram aumento desta propriedade. A análise de textura por cone de penetração revelou que os produtos de ambas as vias apresentaram aumento na profundidade de penetração do cone em relação às amostras antes da reação demonstrando, portanto, o potencial do uso desta reação no aumento da espalhabilidade da gordura do leite.

\section{CONCLUSÃO}

O interesse na substituição da hidrogenação parcial de óleos vegetais por processos que não gerem gordura trans, aliado às descobertas sobre efeitos benéficos à saúde relacionados ao consumo de manteiga, tem incentivado o processo de interesterificação enzimática da gordura do leite visando a obtenção de um produto que alie suas características organolépticas agradáveis a melhores propriedades físicas e nutricionais. Neste processo, aspecto relevante é o uso de lipases como catalisadores, que resulta em via de produção ambientalmente amigável e capaz de reduzir perdas na qualidade sensorial do produto.

Lipases de diversas fontes microbianas têm sido testadas, avaliando-se também o emprego de enzimas imobilizadas como biocatalisadores. Enquanto estudos iniciais empregavam apenas a gordura do leite como matéria-prima, diferentes óleos vegetais passaram a ser empregados na interesterificação com a gordura do leite, em diferentes proporções.

Embora as mudanças composicionais, devidas à interesterificação, sejam preocupações constantes na literatura, os aspectos relacionados às alterações nas propriedades físicas, especialmente a textura do produto sob temperatura de refrigeração, também têm sido relatados em função de sua importância. As modificações no teor de gordura sólida, na consistência e na estrutura cristalina em função da mudança na distribuição dos ácidos graxos nos triacilgliceróis presentes, devem ser cuidadosamente estudadas e relacionadas visando-se o aumento no conhecimento do processo. A análise dos trabalhos da literatura revela que o estudo destes aspectos é uma tendência nos trabalhos científicos, que mostram também preocupação com o uso de matérias-primas poli-insaturadas adicionalmente à gordura do leite.

\section{MATERIAL SUPLEMENTAR}

Está disponível gratuitamente em http://quimicanova.sbq.org.br, na forma de arquivo PDF, com acesso livre. Apresenta a Tabela $1 \mathrm{~S}$, que é um complemento da Tabela 3 apresentada na versão impressa deste artigo; nela está contido o restante dos trabalhos obtidos na pesquisa bibliográfica realizada em diferentes bases de dados científicas (ISI Web of Knowledge, Scopus, Scifinder Scholar) para o período entre 1986 a 2008, utilizando como palavras-chaves: interesterificação enzimática, gordura do leite e lipases. Os trabalhos estão dispostos em ordem cronológica, com os resultados mais relevantes descritos pelos autores.

\section{AGRADECIMENTOS}

Ao apoio financeiro concedido pela FAPESP, CAPES e CNPq.

\section{REFERÊNCIAS}

1. Torres, D.; Casal, S.; Oliveira, M. B. P. P.; Eur. Food Res. Technol. 2002, 214,108

2. Torres, E. A. F. S.; Alimentos do milênio: a importância dos transgênicos, funcionais e fitoterápicos para a saúde, $1^{\mathrm{a}}$. ed., Signus: São Paulo, 2002.

3. Larqué, E.; Zamora, S.; Gil, A.; Early Human Development 2001, 65, 31 .

4. Aued-Pimentel, S.; Caruso, M. S. F.; Cruz, J. M. M.; Kumagai, E. E.; Corrêa, D. U. O.; Rev. Inst. Adolfo Lutz, 2003, 62, 131.

5. Martin, C. A.; Matshushita, M.; Souza, N. E.; Rev. Nutr. 2004, 17, 361.

6. Bertolino, C. N.; Castro, T. G.; Sartorelli, D. S.; Ferreira, S. R. G.; Cardoso, M. A.; Caderno de Saúde Pública 2006, 22, 357.

7. Wardlaw, M. G.; Perspectives in nutrition, $5^{\text {th }}$ ed., Mc Graw Hill: St. Louis, 2002.

8. Roy, A.; Ferlay, A.; Chilliard, Y.; Reprod. Nutr. Dev. 2006, 46, 211.

9. Chiara, V. L.; Sichieri, R.; Carvalho, T. S. F.; Rev. Nutr. 2003, 16, 227.

10. Zegarska, Z.; Paszczyk, B.; Borejszo, Z.; J. Food Lipid 2005, 12, 275.

11. Costa, A. G. V.; Bressan, J.; Sabarense, C. M.; ALAN 2006, 56, 12.

12. Chiara, V. L.; Silva, R.; Jorge, R.; Brasil, A. P.; Rev. Nutr. 2002, 15, 341.

13. Neiva, P.; Revista Veja 2006, 9 agosto, 86.

14. Ghotra, B. S.; Dyal, S. D.; Narine, S. S.; Food Res. Int. 2002, 35, 1015.

15. Ronne, T. H.; Yang, T.; Mu, H.; Jacobsen, C.; Xu, X.; J. Agric. Food Chem. 2005, 53, 5617.

16. Brys, J.; Wirkowska, M.; Ratusz, K.; Kowalski, B.; Tluszcze Jadalne 2006, 41, 123.

17. Brys, J.; Wirkowska, M.; Kowalski, B.; Zywnosc 2006, 13, 28.

18. Zhang, H.; Mu, H.; Xu, X.; Anal. Bioanal. Chem. 2006, 386, 1889.

19. Ronne, T. H.; Jacobsen, C.; Xu, X.; Technol Eur. J. Lipid Sci. 2006, 108, 182.

20. Porsgaard, T.; Overgaard, J.; Krogh, A. L.; Jensen, M. B.; Guo,Z.; Mu, H.; J. Agric. Food Chem. 2007, 55, 7615.

21. Svensson J.; Adlercreutz, P.; Eur. J. Lipid Sci. Technol. 2008, 110, 1.

22. Aguedo, M.; Hanon, E.; Danthine, S.; Paquot, M.; Lognay, G.; Thomas, A.; Vandenbol, M.; Thonart, P.; Wathelet, J.; Blecker, C.; J. Agric. Food Chem. 2008, 56, 1757.

23. Rodrigues, J. N.; Dissertação de Mestrado, Universidade de São Paulo, Brasil, 2002.

24. Balcão, V. M.; Malcata, F. X.; Biotechnol. Adv. 1998, 16, 309.

25. Rodrigues, J. N.; Gioielli, L. A.; Anton, C.; Ciênc. Tecnol. Aliment. 2003, 23, 226.

26. Rodrigues, J. N.; Gioielli, L. A.; Food Res. Int. 2003, 36, 149.

27. Firestone, D.; Physical and Chemical Characteristics of Oils, Fats, and Waxes, $2^{\text {nd }}$ ed. AOCS PRESS: Washington, 2006.

28. Balcão, V. M; Malcata, X. Em Lipid Biotechnology; Kuo, T. M; Gardner, H. W., eds.; Marcel Dekker: New York, 2002, cap. 23.

29. Lock, A. L.; Bauman, D. E.; Lipids 2004, 39, 1197

30. Padilha, P. C.; Pinheiro R. L.; RBC 2004, 50, 251.

31. Orchel, A.; Zewicz, Z.; Parfiniewicz, B.; Weglarz, L.; Wilczok, T.; Digestive Diseases and Sciences 2005, 50, 490.

32. Williams, E. A.; Coxhead, J. M.; Mathers, J. C.; Proc. Nutr. Soc. 2003, $62,107$.

33. Noor Lida, H. M. D.; Sundrama, K.; Siew, W. L.; Aminah, A.; Mamot, S.; J. Am. Oil Chem. Soc. 2002, 79, 1137.

34. Silva, R. C.; Gioielli, L. A.; RBCF 2006, 42, 223. 
35. De Castro, H. F.; Mendes, A. A.; Santos, J. C.; Aguiar, C. L.; Quim. Nova 2004, 27, 146.

36. Carvalho, P. D.; Campos, P. R. B.; Noffs, M. D.; Oliveira, J. G.; Shimizu, M. T.; Silva, D. M.; Quim. Nova 2003, 26, 75.

37. Reetz, T. M.; Curr. Opin. Chem. Biol. 2002, 6, 145.

38. Dalla-Vecchia, R.; Nascimento, M. G.; Soldi, V.; Quim. Nova 2004, 27 , 623.

39. Sharma, R.; Chisti, Y.; Banerjee, U. C.; Biotechnol. Adv. 2001, 19, 627.

40. Jensen, R. G.; Lipids 1983, 18, 650.

41. Queiroz, N.; Tese de Doutorado, Universidade Federal de Santa Catarina, Brasil, 2002.

42. Hasan, F.; Shah, A. A.; Hameed, A.; Enzyme Microb. Technol. 2006, 39, 235.

43. Paula, A. V.; Nunes, G. F. M.; Silva, J. L.; De Castro, H. F.; Santos, J. C.; Appl. Biochem. Biotechnol. 2009, doi 10.1007/s12010-009-8578-z.

44. Faber, K.; Biotransformation in Organic Chemistry: A Textbook, $3^{\text {rd }}$ ed, Springer Produktions-Gesellschaft: Berlin, 1997.

45. Zanin, G. M.; Moraes, F, F. Em Enzimas como Agentes Biotecnológicos; Said, S.; Pietro, R. C. L. R., eds.; Legis Summa: Ribeirão Preto, 2004, cap. 4 .

46. De Castro, H. F.; Zanin, G. M.; Moraes, F. F.; Sá-Pereira, P. Em Enzimas em biotecnologia: Produção, aplicação e mercado; Bon, E. P. S.; Ferrara, M. A.; Corvo, M. L.; Vermelho, A. B.; Paiva, C. L. A.; Alencastro, R. B.; Coelho, R. R. R., eds; Interciência: Rio de Janeiro, 2008, cap. 6.

47. Atia, K. S.; El-arnaouty, M. B.; Ismail, S. A.; Dessouki, A. M. J.; Appl. Polym. Sci. 2003, 90, 155.

48. Pandey, A.; Benjamin, S.; Soccol, C. R.; Nigam, P.; Krieger, N.; Thomazsoccol, V.; Biotechnol. Appl. Biochem. 1999, 65, 252.

49. Lawson, H.; Food Oils and Fats: Technology, utilization, and nutrition, Chapman \& Hall: London, 1995.

50. Rodríguez, A.; Castro, E.; Salinas, M. C.; López, R.; Miranda, M.; J. Am. Oil Chem. Soc. 2001, 78, 431.

51. Yu, Z.; Rizvi, S. S. H.; Zollwegf, J. A.; Biotechnol. Prog. 1992, 8, 508.

52. Balcão, V. M.; Kemppinem, A.; Malcata, F. X.; Kalo, P. J.; J. Am. Oil Chem. Soc. 1998, 75, 1347.

53. Rousseau, D.; Marangoni, A. G.; Food Res. Int. 1999, 31, 381.

54. Lai, O. M.; Ghazali, H. M.; Cho, F.; Chong, C. L.; Food Chem. 2000, $70,221$.
55. Kalo, P.; Parviainen, P.; Vaara, K.; Ali-Yrrko, S.; Antila, M.; Milchwissenschaft 1986, 41, 82.

56. Kalo, P.; Perttila, M.; Kemppinen, A.; Antila, M.; Meijeritieteellinen Aikakauskirja 1988, 46, 36.

57. Kalo, P.; Huotari, H.; Antila, M.; Fett Wissenschaft Technologie 1989, 91, 276.

58. Kalo, P.; Huotari H.; Antila, M.; Meijeritieteellinen Aikakauskirja 1989, $47,29$.

59. Kalo, P.; Huotari, H.; Antila, M.;Milchwissenschaft 1990, 45, 281.

60. Foglia, T. A.; Petruso, K.; Feairheller, S. H.; J. Am. Oil Chem. Soc. 1993, $70,281$.

61. Rousseau, D.; Marangoni, A. G.; J. Agric. Food Chem. 1998, 46, 2368.

62. Rousseau, D.; Marangoni, A. G.; J. Agric. Food Chem. 1998, 46, 2375.

63. Marangoni, A. G.; Rousseau, D.; Food Res. Int. 1999, 31, 595.

64. Chmura, M.; Staniewski, B.; Polish J. Nat. Sci. 2002, 11, 27.

65. Brys, J.; Gruczynska, E.; Kowalski, B.; Tarnowska, K.; Zywnosc 2004, $11,18$.

66. Brys, J.; Gruczynska, E.; Wirkowska, M.; Kowalski, B.; Gozdowski, D.; Tluszcze Jadalne 2005, 40, 80.

67. Wirkowska, M.; Brys, J.; Kowalski, B.; Zywnosc 2005, 12, 265.

68. Safari, M.; Kermasha, S.; Pabai, F.; Food Biotechnol. 1993, 7, 265.

69. Wirkowska, M.; Brys, J.; Tarnowska, K.; Kowalski, B.; Gozdowski, D.; Tluszcze Jadalne 2005, 40, 91.

70. Lee, P.; Swaisgood, H. E.; J. Agric. Food Chem. 1997, 45, 3343.

71. Liew, M. Y. B.; Ghazali, H. M., Long, K.; Lai, O. M.; Yazid, A. M.; Food Chem. 2001, 72, 447.

72. Brys, J.; Kowalska, M.; Wirkowska, M.; Kowalski, B.; Folia Universitatis Agriculturae Stetinensis 2005, 246, 23.

73. Safari, M.; Kermasha, S.; J. Am. Oil Chem. Soc. 1994, 71, 969.

74. Nor Hayati, I.; Aminah, A.; Mamot, S.; J. Food Lipids 2000, 7, 175.

75. Liew, M. Y. B.; Ghazali, H. M.; Yazid, A. M.; La1, O. M.; J. Food Lipids 2001, 8, 131.

76. Pabai, F.; Kermasha, S.; Morin, A.; World J. Microbiol. Biotechnol. 1995, 11, 669 .

77. Habulin, M.; Primožič, M.; Knez, Ž.; Acta Chim. Slov. 2007, 54, 667.

78. Saldaña, M. D. A.; Mazzafera, P.; Mohamed, R. S.; Ciênc. Tecnol. Aliment. 1997, 17, 371. 


\section{MODIFICAÇÃO BIOQUÍMICA DA GORDURA DO LEITE}

\section{Gisele Fátima Morais Nunes, Ariela Veloso de Paula e Heizir Ferreira de Castro}

Escola de Engenharia de Lorena, Universidade de São Paulo, CP 116, 12602810 Lorena - SP, Brasil

Júlio César dos Santos*

Departamento de Ciências Agrárias, Universidade de Taubaté, Estrada Dr. José Luiz Cembranelli, 5.000, 12081-010 Taubaté - SP, Brasil

A Tabela 1S é um complemento da Tabela 3 apresentada no corpo da versão impressa da revista; nela está contido o restante dos trabalhos obtidos na pesquisa bibliográfica realizada em diferentes bases de dados científicas (ISI Web of Knowledge, Scopus, Scifinder Scholar) para o período entre 1986 a 2008, utilizando como palavras-chaves: interesterificação enzimática, gordura do leite e lipases. Os trabalhos estão dispostos em ordem cronológica, com os resultados mais relevantes descritos pelos autores.

Tabela 1S. Exemplos de estudos realizados sobre a interesterificação enzimática da gordura do leite

\begin{tabular}{lcc}
\hline Biocatalisador & Matérias-primas & Condições reacionais \\
\hline $\begin{array}{l}\text { C. cilyndracae } \\
\text { imobilizada em Celite }\end{array}$ & Gordura do leite & $\begin{array}{c}\text { Frascos agitados; } \\
\text { presença e ausência de } \\
\text { solvente (hexano) } \\
\text { a } 40^{\circ} \mathrm{C} .\end{array}$ \\
$\begin{array}{l}\text { Lipozyme TM } \\
\text { A. } \text { niger } \\
\text { imobilizada em Celite }\end{array}$ & Gordura do leite & $\begin{array}{c}\text { Frascos agitados solvente (iso- } \\
\text { octano); a } 35^{\circ} \mathrm{C} \text { para lipase de } \\
\text { A.niger e } 60^{\circ} \mathrm{C} \text { para } \\
\text { lipase de } M \text {. miehei. }\end{array}$ \\
& & \\
P. fluorescens & & \\
imobilizada em Celite & Gordura do leite & Variação da quantidade de \\
& & água do meio reacional.
\end{tabular}

Houve redução dos TAGs $\mathrm{C}_{36}$ e $\mathrm{C}_{38}$ e elevação dos TAGs $\mathrm{C}_{44} \mathrm{e}_{50}$. Os produtos obtidos por via química e enzimática foram similares em composição, a lipase empregada não apresentou especificidade. A gordura interesterificada com biocatalisador apresentou-se mais macia devido à presença dos mono e diglicerídeos formados.

Os produtos apresentaram composição em TAGs diferentes da gordura do leite antes da interesterificação, porém apresentaram composições semelhantes para a reação catalisada por ambas as lipases. As enzimas estudadas não são específicas sob as condições de reação empregadas.

Os produtos apresentaram composição em TAGs diferentes da gordura do leite antes da interesterificação, porém apresentaram composições semelhantes para a reação realizada sob diferentes condições reacionais. O conteúdo 57 de produtos hidrolisados é dependente da quantidade de água presente no meio reacional.

P.fluorescens $\quad$ Gordura do leite imobilizada em Celite

\section{P. fluorescens imobilizada em Celite}

Gordura do leite
Lipozyme;
R. delemar
imobilizada em Celite;
G. candidum imobilizada
em AcurelEP 100
Gordura do leite Óleo de girassol ácido oleico enriquecido com

solvente (isooctano); baixo teor de água; diferentes temperaturas.

Baixo teor de água; sem ou com solvente (isooctano); 40-60 ${ }^{\circ} \mathrm{C}$.

Frascos agitados (100 rpm); $60^{\circ} \mathrm{C}$.
Os produtos apresentaram composição em TAGs similares para a reação realizada sob as diferentes temperaturas estudadas, portanto a temperatura não afetou a posição especifica de rearranjo dos AG no TAGs.

Os produtos apresentaram composição em TAGs similares para a interesterificação realizada sob diferentes temperaturas e meios reacionais (com e sem solvente). Apresentaram também propriedades de fusão semelhantes.

O grau de hidrólise das misturas de gordura/óleo foi dependente da quantidade de água inicial no meio reacional. O tempo de reação foi dependente da quantidade de enzima utilizada, mas não da temperatura

*e-mail: jsant200@yahoo.com.br

55

6


Tabela 1S. continuação

Biocatalisador Matérias-primas Condições reacionais Refultados

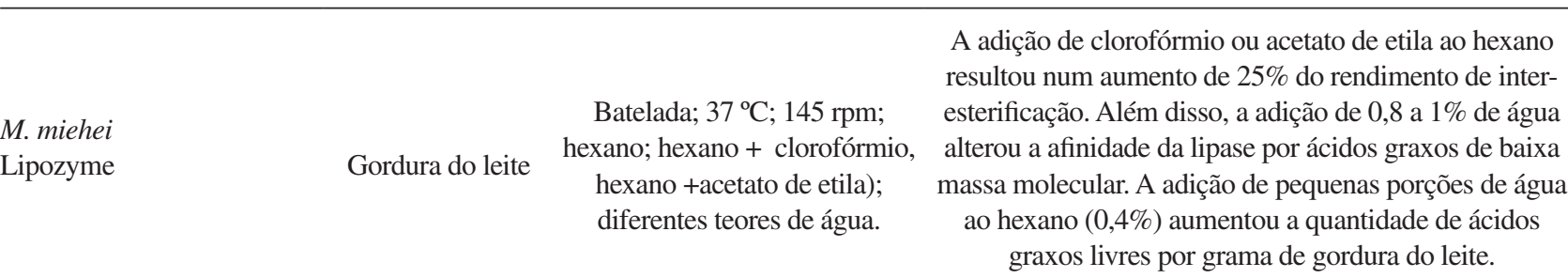

Ref.

Lipozyme; R. delemar; Rhizopus niveus; Mucor javanicus

P. putida; A. niger;

R. oryzae

\section{P. fluorescens} imobilizada em vidro poroso

Rhizopus arrhizus imobilizada em polipropileno

Gordura do leite Óleo de canola

\section{R. arrhizus}

imobilizada em polipropileno

\section{R. arrhizus} imobilizada em polipropileno

Gordura do leite Óleo de canola

Gordura do leite Óleo de canola

Sem solvente; 40-60 ${ }^{\circ} \mathrm{C}$; $\mathrm{pH}$ 6-8; conteúdo inicial de água $0,1-1,0 \%$.

Meio isento de solvente; 40-60 ${ }^{\circ} \mathrm{C}$; pH 6-8; conteúdo inicial de água $0,1-1,0 \%$.

Frascos agitados $(250 \mathrm{rpm})$ 60-70 ${ }^{\circ} \mathrm{C}$.
Os resultados mostraram a afinidade hidrolítica das lipases por ácidos graxos de baixa massa molecular (C4:0C14:0). A análise da esterioespecificidade dos ácidos graxos presentes nos TAGs da gordura do leite interesterificada catalisada pela lipase de $R$. niveus demonstrou um aumento de $46 \%$ na proporção de $\mathrm{C} 18: 1$ cis $\Delta^{9}$ na posição $s n-2$, enquanto que os produtos da reação catalisada pelas lipases de M. miehei, R. delemar e M. javanicus foram enriquecidos com 21, 35 e $41 \%$ de C16:0, respectivamente, na mesma posição dos TAGs.

Os resultados mostraram que a lipase de A. niger teve o mais alto rendimento de interesterificação (26\%). Esta lipase foi também a que mostrou mais elevado decréscimo (17\%) dos ácidos graxos de cadeia longa hipercolesterolemicos (C12:0, C14:0 e C16:0) na posição $s n-2$.

A composição em TAGs dos produtos obtidos foi distinta da composição da matéria-prima, pois houve um decréscimo dos TAGs $\mathrm{C}_{36}-\mathrm{C}_{42}$ e um aumento nos TAGs $\mathrm{C}_{48}-\mathrm{C}_{50}$. O produto apresentou temperatura de fusão e CGS mais baixo que o apresentado pela gordura do leite.

Para misturas com maior proporção de óleo de canola, maiores alterações em TAGs foram observadas. A taxa de hidrólise inicial foi dependente do conteúdo inicial de água na faixa de 0-0,55\% de água. Os AGL predominantes foram C18:1 e C16:0.

Os produtos apresentaram perfis de CGS em função da temperatura mais baixos que o das misturas. $\mathrm{O}$ ponto de gota (dropping point) como função da proporção de óleo de canola decresceu após a reação de forma mais acentuada que para as misturas. Tanto a mistura quanto a interesterificação diminuiram a dureza da gordura do leite.

A interesterificação da gordura do leite levou ao decréscimo dos TAGs $\mathrm{C}_{32}-\mathrm{C}_{42}$ e aumento dos TAGs $\mathrm{C}_{44}-\mathrm{C}_{54}$. O CGS da gordura do leite e da mistura (80:10) após reação enzimática reduziu para todas as temperaturas estudadas. A dureza e o módulo de estocagem da gordura do leite e das misturas acima de (70:30) decresceram com a reação.

A análise por DSC indicou que a interesterificação reduziu o número de picos distintos de fusão e a entalpia de fusão, sendo observado um decréscimo no conteúdo de gordura 74 sólida na faixa de temperatura de $25-40{ }^{\circ} \mathrm{C}$. 
Tabela 1S. continuação

\begin{tabular}{|c|c|c|c|}
\hline Biocatalisador & Matérias-primas & Condições reacionais & Principais Resultados \\
\hline $\begin{array}{l}\text { R. miehei } \\
\text { (células íntegras não viáveis) } \\
\text { Lipozyme IM60 }\end{array}$ & $\begin{array}{l}\text { Gordura do leite } \\
\text { Oleína de palma }\end{array}$ & $\begin{array}{l}\text { Frascos agitados } \\
\text { (200 rpm); } \\
60^{\circ} \mathrm{C}\end{array}$ & $\begin{array}{l}\text { Ambas as enzimas foram capazes de produzir misturas } \\
\text { com um novo perfil de TAGs, que apresentaram geral- } \\
\text { mente um ponto de deslizamento e CGS mais baixos. } \\
\text { Os termogramas obtidos por DSC indicaram mudanças } \\
\text { na composição cristalina dos TAGs e uma alteração nos } \\
\text { TAGs de mais baixos pontos de fusão. A Lipozyme IM60 } \\
\text { produziu maior rendimento de interesterificação (43- } \\
51 \%) \text {. }\end{array}$ \\
\hline $\begin{array}{l}\text { R. miehei } \\
\text { (células íntegras) }\end{array}$ & $\begin{array}{l}\text { Gordura do leite } \\
\text { Oleína de palma }\end{array}$ & $\begin{array}{l}\text { Frascos agitados } \\
\qquad(200 \mathrm{rpm}) \\
\quad 60^{\circ} \mathrm{C}\end{array}$ & $\begin{array}{l}\text { Os resultados indicaram que a emulsão preparada usando } \\
\text { a mistura interesterificada exibe um comportamento } \\
\text { reológico diferente da gordura do leite pura e da mistura } \\
\text { não modificada. }\end{array}$ \\
\hline Lipozyme IM & $\begin{array}{l}\text { Gordura do leite } \\
\text { Óleos de soja, giras- } \\
\text { sol, colza e palma. }\end{array}$ & $\begin{array}{l}65^{\circ} \mathrm{C} \\
24 \mathrm{~h}\end{array}$ & $\begin{array}{l}\text { Os resultados mostraram redução no conteúdo dos TAGs } \\
\mathrm{C}_{34}-\mathrm{C}_{40} \text { e aumento dos TAGs de cadeia longa. Houve de- } \\
\text { créscimo do conteúdo de gordura sólido em temperaturas } \\
\text { entre } 0 \text { e } 15^{\circ} \mathrm{C} \text { e aumento desta propriedade acima de } 22,5 \\
{ }^{\circ} \mathrm{C} \text {.Os produtos apresentaram elevação do ponto de fusão e } \\
\text { diminuição da dureza a } 5^{\circ} \mathrm{C} \text {. }\end{array}$ \\
\hline
\end{tabular}

Ref.

\section{R. miehei}

(células íntegras não viáveis)

Lipozyme IM60

Gordura do leite

Óleos de soja, giras-

sol, colza e palma

Novozym 435

Lipozyme RM- IM

Óleo de colza

Novozym 435

Lipozyme RM- IM

Novozyme 435

Lipozyme RM- IM

Novozym 435

Novozym 435
Gordura do

leite

2,4 e $8 \mathrm{~h}$

$50,60,70$ e $80^{\circ} \mathrm{C}$.

Óleo de colza

$2-8 \mathrm{~h}$

Tanto a interesterificação química quanto a enzimática aumentaram o conteúdo de AG livres e de frações polares (mono e diglicerídeos), a via química apresentou os teores mais elevados.

Após a interesterificação houve elevação do conteúdo AGL e da fração polar. O conteúdo de gordura sólida e a temperatura de fusão dos TAGs resultantes da reação decresceram quando comparados aos da mistura inicial das matérias-primas.

Após a reação houve elevação do conteúdo AGL e dos mono e diglicerídeos. O conteúdo de gordura sólida

Gordura do leite e a temperatura de fusão dos TAGs resultantes foram

2,4 e 8 h; $50,60,70$ e $80^{\circ} \mathrm{C}$ mais elevados que da matéria-prima. A interesterificação melhorou as propriedades físicas da gordura do leite.

Os produtos apresentaram decréscimo da estabilidade oxidativa em comparação à mistura inicial das matérias-primas. Esse decréscimo foi mais relevante quando foi utilizado catalisador químico e menos acentuado na reação em que Lipozyme RM- IM foi empregada como biocatalisador.

Os produtos apresentaram decréscimo da estabi$8 \mathrm{~h} ; 70^{\circ} \mathrm{C}$. leite Óleo de colza

Gordura do leite Óleo de girassol
2,4 e $8 \mathrm{~h}$ 70 e $80{ }^{\circ} \mathrm{C}$. lidade oxidativa em comparação à mistura inicial das matérias-primas.

Após a interesterificação houve elevação do conteúdo AG livres para todas as misturas. O conteúdo de gordura sólida e a temperatura de fusão dos produtos resultantes da reação foram dependentes da composição da mistura antes do processo. 
Tabela 1S. continuação

\begin{tabular}{|c|c|c|c|c|}
\hline Biocatalisador & Matérias-primas & Condições reacionais & Principais Resultados & Ref. \\
\hline Lipozyme TL IM & $\begin{array}{l}\text { Gordura de leite } \\
\text { Óleo de colza }\end{array}$ & $\begin{array}{c}\text { Reator de leito } \\
\text { empacotado } 60^{\circ} \mathrm{C} \text {. }\end{array}$ & $\begin{array}{l}\text { A melhor condição de remoção do aroma indesejável } \\
\text { do produto foi obtida com desodorização a } 120^{\circ} \mathrm{C} \text { por } \\
2 \mathrm{~h} \text {. }\end{array}$ & 19 \\
\hline Lipozyme TL IM & $\begin{array}{l}\text { Gordura do leite } \\
\text { Óleo de colza }\end{array}$ & $\begin{array}{l}\text { Batelada } \\
60^{\circ} \mathrm{C} \\
24 \mathrm{~h}\end{array}$ & $\begin{array}{l}\text { Devido à regiosseletividade da lipase, a reação de in- } \\
\text { teresterificação envolveu principalmente ácidos graxos } \\
\text { nas posições } s n-1 \text { e } s n \text { - } 3 \text {. Entretanto, mudanças signifi- } \\
\text { cativas na composição de ácidos graxos na posição } \\
\quad s n-2 \text { foram detectadas após } 6 \text { h de reação. }\end{array}$ & 21 \\
\hline
\end{tabular}

TAGs=Triacilgliceróis; CGS= Conteúdo de gordura sólida; AGL = Ácidos graxos livres; DSC= Differential scanning calorimetry (calorimetria exploratória diferencial); 